\title{
Oxygen Defects Mediated Magnetism of Ni Doped ZnO
}

\author{
W. J. Liu, ${ }^{1}$ X. D. Tang, ${ }^{2}$ Z. Tang, ${ }^{2}$ W. Bai, ${ }^{2}$ and N. Y. Tang ${ }^{1}$ \\ ${ }^{1}$ Shanghai University of Electric Power, 2588 Pingyang Road, Shanghai 200090, China \\ ${ }^{2}$ East China Normal University, 500 Dongchuan Road, Shanghai 200241, China \\ Correspondence should be addressed to W. J. Liu; liuwj5500@gmail.com
}

Received 23 July 2013; Revised 2 September 2013; Accepted 16 September 2013

Academic Editor: Xuan Luo

Copyright (C) 2013 W. J. Liu et al. This is an open access article distributed under the Creative Commons Attribution License, which permits unrestricted use, distribution, and reproduction in any medium, provided the original work is properly cited.

\begin{abstract}
$\mathrm{Ni}$ doped $\mathrm{ZnO}$ nanoparticles were synthesized by a solution route and annealed in $\mathrm{O}_{2}$, air, and Ar, respectively. X-ray diffraction and X-ray photoelectron spectroscopy measurements show that the samples possess typical wurtzite structure and have no other impurity phases. Magnetization loops for $\mathrm{ZnO}$ samples were measured and clearly show typical ferromagnetic saturation behavior. With the defect analysis based on photoluminescence spectroscopy, the effect of defects on the nature and origin of ferromagnetism was investigated. The results suggest that oxygen vacancies, especially single ionized oxygen vacancies, play a crucial role in mediating ferromagnetism in the $\mathrm{Ni}$ doped $\mathrm{ZnO}$.
\end{abstract}

\section{Introduction}

Diluted magnetic oxide semiconductors (DMOSs) have gained much attention recently due to the possibility to control spin and charge simultaneously for future spintronics $[1,2]$. These oxide semiconductors with a wide band gap are optically transparent in visible region and important for the development of spin related optoelectronic devices. After the theoretical prediction by Dietl et al. suggesting the existence of room temperature ferromagnetism (FM) in doped $\mathrm{ZnO}$, the system has been extensively studied $[3,4]$. Remarkable progress has been made in the realization of transition metal (TM) doped $\mathrm{ZnO}$ with Curie temperature $\left(T_{c}\right)$ at or above room temperature (RT). It was also reported that even doping "nonmagnetic" atoms such as $\mathrm{Cu}$ or Bi leads to RT FM in ZnO $[5,6]$. More recently, FM had been observed in undoped $\mathrm{ZnO}$, which opened an extensive debate on the origin of FM [7, 8]. Therefore, some researches suggested that induced FM is due to oxygen defects in $\mathrm{ZnO}$, not TM ions or secondary phases. Although the origin of FM in TM doped and undoped $\mathrm{ZnO}$ has not been fully understood so far, oxygen (or $\mathrm{Zn}$ ) defects are broadly recognized as an important reason for the FM behavior of doped and undoped $\mathrm{ZnO}$, which is also consistent with our previous work on FM of undoped $\mathrm{ZnO}$ [9].

In the present work, we have focused our attention on further research of the role of oxygen (or $\mathrm{Zn}$ ) defects by investigating the effect of different annealing atmospheres on the FM properties of $\mathrm{Ni}$ doped $\mathrm{ZnO}$ nanoparticles based on an analysis of photoluminescence (PL) spectroscopy.

\section{Experimental}

2.1. Preparation of Ni Doped ZnO Nanoparticles. Ni doped $\mathrm{ZnO}$ nanoparticles were prepared by a solution method. A total of $0.01 \mathrm{~mol}$ of zinc acetate $\left(\mathrm{Zn}(\mathrm{AC})_{2} \cdot 2 \mathrm{H}_{2} \mathrm{O}\right)$ and Nickel acetate $\left(\mathrm{Ni}(\mathrm{AC})_{2} \cdot 4 \mathrm{H}_{2} \mathrm{O}\right)$ in the chosen atomic rations were dissolved in $200 \mathrm{ml}$ deionized water as the precursor together with 0.01 mol methenamine $\left(\mathrm{C}_{6} \mathrm{H}_{12} \mathrm{~N}_{4}, \mathrm{HMT}\right)$. Then they were mixed under vigorous stirring for $30 \mathrm{~min}$ in a glass beaker. Before growth, a glass substrate was cleaned carefully and put into the glass beaker. The growth time and temperature were $24 \mathrm{~h}$ and $95^{\circ} \mathrm{C}$, respectively. After growth, the substrate was taken out the solution, thoroughly rinsed with deionized water, treated in an ultrasonic water bath for $10 \mathrm{~min}$, and dried in air at room temperature. To investigate the influence of defects on the inducing magnetic moment, the resulting sample was divided into three parts for the followed anneal at $800^{\circ} \mathrm{C}$ for $30 \mathrm{~min}$ in $\mathrm{Ar}$, air, and $\mathrm{O}_{2}$, respectively.

2.2. Characterization. The structure of $\mathrm{Ni}$ doped $\mathrm{ZnO}$ nanoparticles was determined by X-ray diffraction (XRD) with $\mathrm{Cu} K a$ radiation $(\lambda=0.1542 \mathrm{~nm})$ at $\mathrm{RT}$. The effective concentration and binding state of the ions in the 


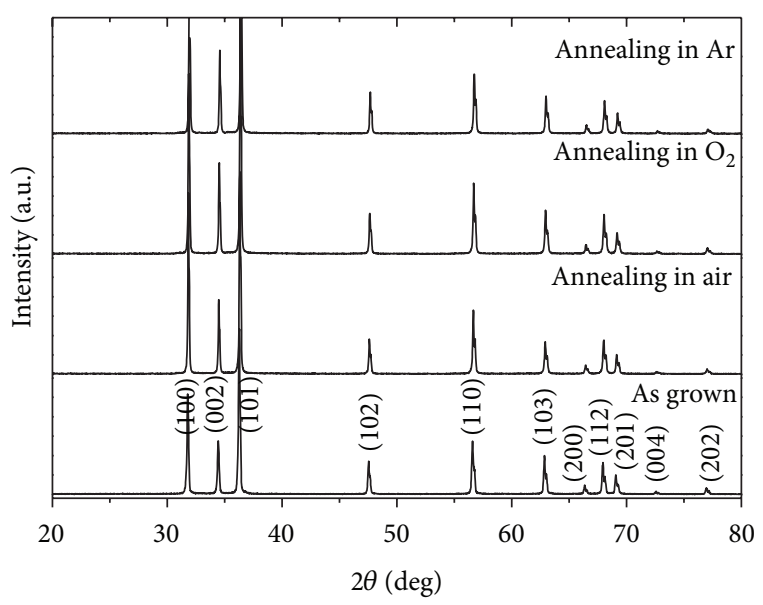

Figure 1: X-ray diffraction of $\mathrm{Ni}$ doped $\mathrm{ZnO}$ samples as grown and thermal annealed in different atmosphere.

nanostructures were characterized with X-ray photoelectron spectroscopy (XPS) (ESCA-LAB 250, Thermo-VG Scientific). The optical properties were characterized by photoluminescence (JobinYvon-800 HR). The magnetic properties were investigated by means of a SQUID magnetometer (MPMS, Quantum Design-PPMS 9).

\section{Results and Discussion}

3.1. Microstructure. The structure of $\mathrm{Ni}$ doped $\mathrm{ZnO}$ particles was characterized by XRD at RT, as shown in Figure 1. No other diffraction peaks besides those of wurtzite $\mathrm{ZnO}$ can be observed. Thus, it was demonstrated that the samples possess the typical wurtzite structure and no impurity phases are present.

3.2. XPS Analysis. X-ray photoelectron spectroscopy is the most useful tool to analyze the surface valence states of the elements in a material. To further investigate the composition and structure of the prepared particles, XPS spectra of Ni doped $\mathrm{ZnO}$ sample were measured and are shown in Figure 2.

An extended scan is reproduced in Figure 2(a). The $\mathrm{Zn} 2 \mathrm{p} 3$ spectrum exhibits an asymmetry feature, indicating the possibility of existence of multicomponent $\mathrm{Zn}$. Gaussian resolving is performed and two peaks obtained were centered at 1020.93 and $1022.42 \mathrm{eV}$ (see Figure 2(b)). The peak centered at $1020.93 \mathrm{eV}$ corresponds to the binding energies of $\mathrm{Zn} 2 \mathrm{p} 3$ of undoped $\mathrm{ZnO}$. The peak centered at $1022.42 \mathrm{eV}$ is attributed to the $\mathrm{Zn} 2 \mathrm{p} 3$ of $\mathrm{Ni}$ doped $\mathrm{ZnO}$. This increase of binding energy is due to the substitution of parts of the lattice $\mathrm{Zn}$ in $\mathrm{ZnO}$ by $\mathrm{Ni}^{2+}$ ions with the larger ionic radius and the formation of $\mathrm{Zn}-\mathrm{Ni}$ bonding structure.

To investigate the distributing of $\mathrm{Ni}$ element, gaussian resolving is also performed on the $\mathrm{Ni} 2 \mathrm{p}$ spectrum. The peaks of $\mathrm{Ni} 2 \mathrm{p} 3 / 2$ and $\mathrm{Ni} 2 \mathrm{pl} / 2$ core levels are found to be centered at 855.54 and $873.1 \mathrm{eV}$, respectively, whereas the corresponding satellite structures are clearly observed at 861.3 and $878.7 \mathrm{eV}$. The peak positions depend on the local structure of the $\mathrm{Ni}$ atoms and provide the information about the chemical state. The Ni 2p3/2 (855.54 eV) position is quite different from that of metallic $\mathrm{Ni}(852.7 \mathrm{eV}), \mathrm{NiO}$ $(853.8 \mathrm{eV})$, and $\mathrm{Ni}_{2} \mathrm{O}_{3}(856.7 \mathrm{eV})$. The absence of Ni metallic clusters can also be explained on the basis of energy difference between $\mathrm{Ni} 2 \mathrm{p} 3 / 2$ and $\mathrm{Ni}$ 2p1/2 core levels. For Ni doped $\mathrm{ZnO}$, the difference is $17.56 \mathrm{eV}$, which is different from the value of metallic $\mathrm{Ni}(17.27 \mathrm{eV})$. This energy difference for $\mathrm{NiO}(17.49 \mathrm{eV})$ is very close to the observed $(17.56 \mathrm{eV})$ value, which gives the evidence that $\mathrm{Ni}$ is in +2 valance state; however, the presence of $\mathrm{NiO}$ can be ruled out as $\mathrm{NiO}$ is antiferromagnetic (TN $520 \mathrm{~K}$ ), whereas in this case, room temperature ferromagnetism is observed. Furthermore, the shape of peaks for $\mathrm{Ni}$ metallic with satellites structure is narrow and different from the observed spectrum of $\mathrm{Ni}$ doped $\mathrm{ZnO}$ nanorods. These results give evidence that $\mathrm{Ni}$ ions with valence +2 are successfully substituted into tetrahedral sites of the $\mathrm{ZnO}$ wurtzite structure without forming any detectable impurity phase, such as Ni metal, $\mathrm{Ni}_{2} \mathrm{O}_{3}$, and $\mathrm{NiO}$. The atomic concentration of $\mathrm{Ni}$ is about $2.90 \%$.

The XPS spectrum of O1s is asymmetric (see Figure 2(d)), indicating the presence of multicomponent oxygen species in the near-surface region. It can be fitted with three components, which are centered at $529.92 \mathrm{eV}, 531.2 \mathrm{eV}$, and $531.74 \mathrm{eV}$, respectively. The peak at about $529.92 \mathrm{eV}$ is attributed to the $\mathrm{ZnNiO}$ crystal lattice oxygen. The peak at about $531.2 \mathrm{eV}$ is associated with oxygen-deficient regions in the $\mathrm{ZnNiO}$ matrix. The peak at about $531.74 \mathrm{eV}$ is due to the chemisorbed oxygen of the surface hydroxyl, $-\mathrm{CO}_{3}$, absorbed $\mathrm{H}_{2} \mathrm{O}$, or absorbed $\mathrm{O}_{2}[10-12]$.

3.3. Photoluminescence Properties. To investigate the presence of defects, the RT PL spectra of Ni doped $\mathrm{ZnO}$ as grown and annealed at three different atmospheres are shown in Figure 3(a). Each spectrum displays ultraviolet (UV) near band-edge (NBE) emission. It is well known that, at RT, $\mathrm{ZnO}$ typically exhibits UV band-edge emission and broad visible emissions at green, orange, yellow, and red spectral bands. The UV band-edge emission is attributed to free excitonic emission. It is reasonable to assume that this PL mechanism is the same for all our investigated $\mathrm{Ni}$ doped $\mathrm{ZnO}$ samples. We observed the UV near-band-edge emission peak at 380-400 nm. Here, we only report data for visible emission, which is referred to as deep-level emission and attributed to recombination of electrons deeply trapped in oxygen/Zn vacancies and interstitials, with photo-generated holes.

Many reports have focused on the origin of the PL in doped and undoped $\mathrm{ZnO}$. There are three peaks in the visible band, $527 \mathrm{~nm}, 575 \mathrm{~nm}$, and $657 \mathrm{~nm}$. The green emission $(527 \mathrm{~nm})$ is generally attributed to the recombination of electrons trapped in single ionized oxygen vacancies $\left(V_{o}^{+}\right)$ with photo generated holes $[13,14]$. The green emission $(575 \mathrm{~nm})$ is related to the doubly ionized oxygen vacancy $\left(V_{o}^{++}\right)$[15-17]. The red emission around $657 \mathrm{~nm}$ originates from the intrinsic defects of oxygen interstitials) $\left(\mathrm{O}_{i}\right)$ [18-20], which act as traps for photo-generated holes. 


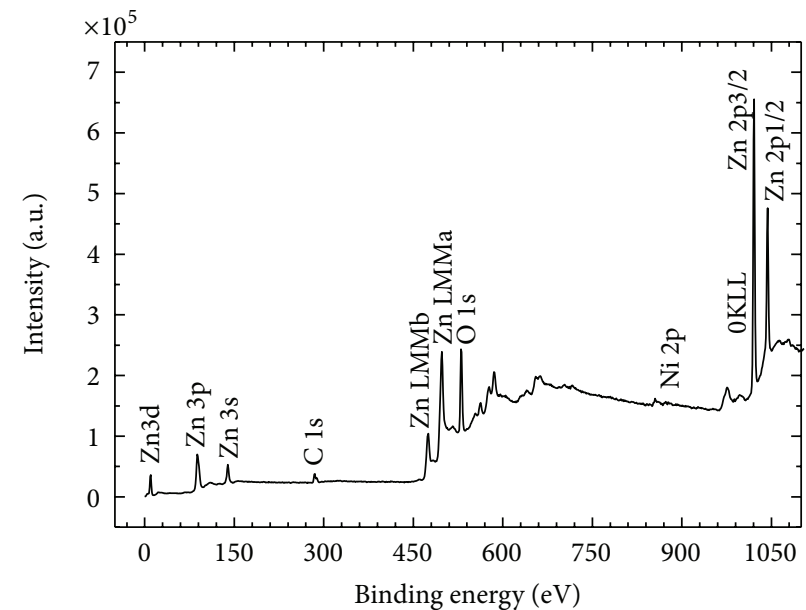

(a)

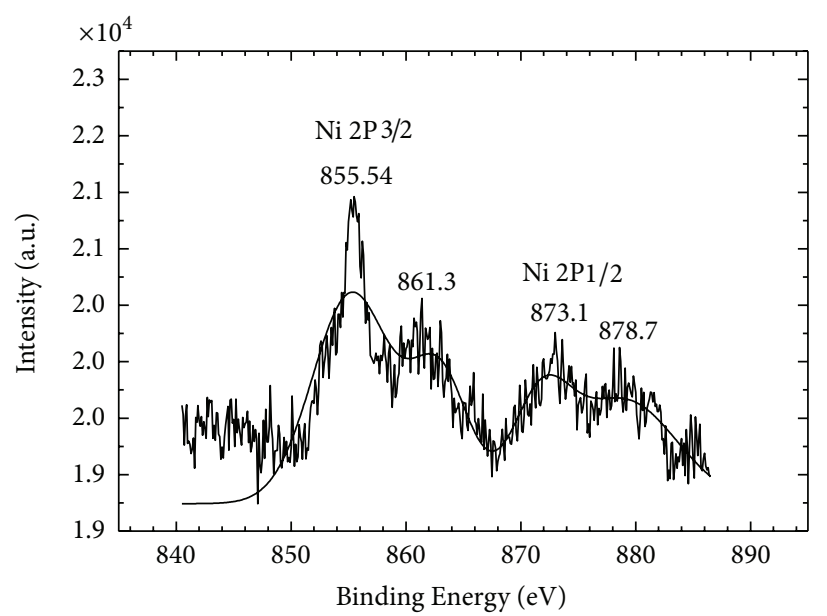

(c)

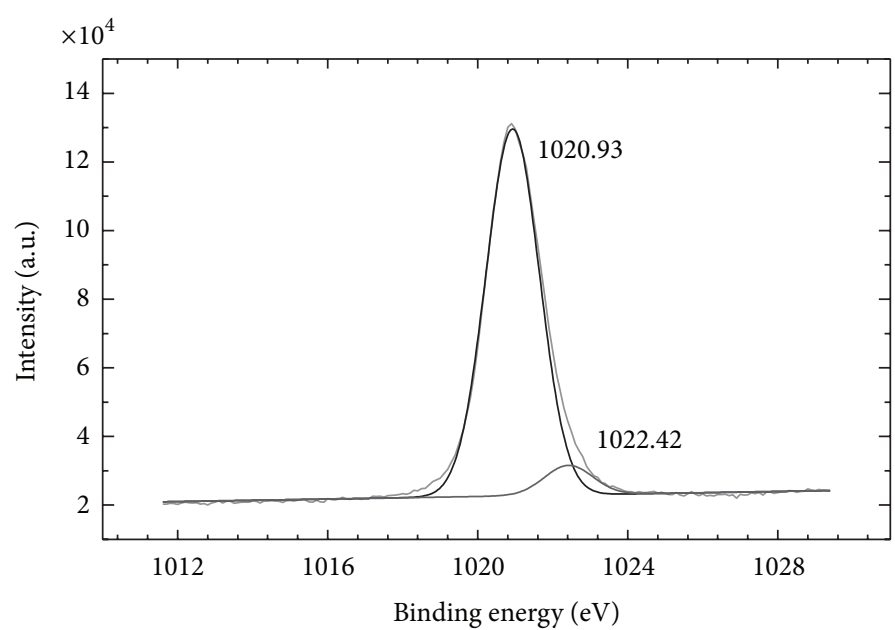

(b)

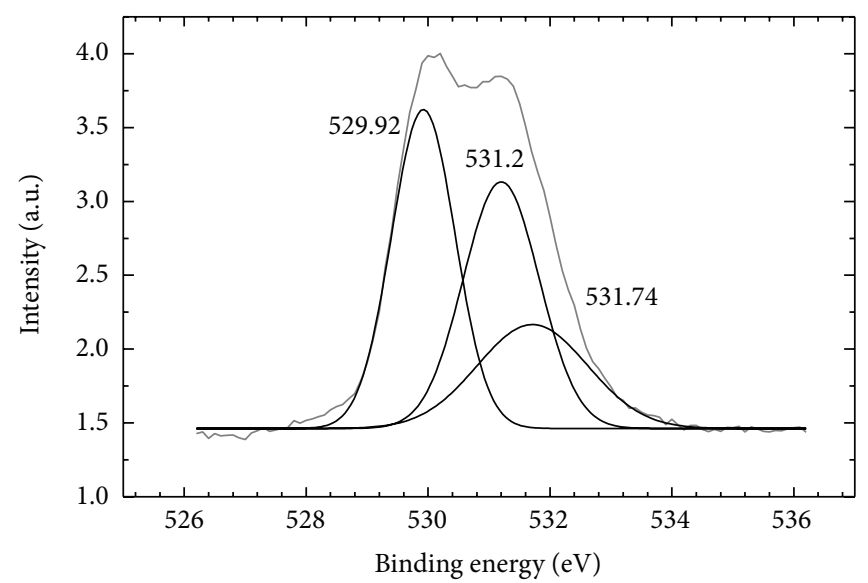

(d)

FIGURE 2: XPS spectra of as grown Ni doped ZnO samples: (a) Extended scan; (b) Zn2p3 spectrum; (c) Ni2p3 spectrum; (d) O1s spectrum. (The gray lines represent experimental results and the black solid curves are Gaussian fits of the components).

Gaussian fitting is performed on each spectrum to investigate the distributing of the above three defects, which is shown in Figure 3(b). Figure 4 displays the contents of oxygen related defects in $\mathrm{Ni}$ doped $\mathrm{ZnO}$ samples as grown and postannealed in different atmospheres $\left(\mathrm{O}_{2}\right.$, air, and $\left.\mathrm{Ar}\right)$.

During the annealing process in $\mathrm{Ar}$ and air, oxygen easily escapes from the $\mathrm{ZnO}$ particles, the concentration of oxygen vacancies $\left(V_{o}^{+}\right.$and $\left.V_{o}^{++}\right)$increases, and the concentration of $\mathrm{O}_{i}$ decreases. After annealed in $\mathrm{O}_{2}$, the oxygen vacancies in the sample are filled to a large extent and the concentration of oxygen interstitials have increased. At the same time, the relative contents of $V_{o}^{+}$increases due to the fact that part of $V_{o}^{++}$have been transformed into $V_{o}^{+}$during the annealing process.

3.4. Magnetic Properties. Magnetization loops for the samples in capsules were measured at $300 \mathrm{~K}$ using a VSM magnetometer and the $\mathrm{M}-\mathrm{H}$ curves are shown in Figure 5. The actual magnetization of the samples was determined by subtracting the diamagnetic contribution of the capsule and substrate from the raw data. Our experimental results presented indeed show that all the samples are ferromagnetic at RT. The $\mathrm{M}-\mathrm{H}$ curves clearly show that the typical ferromagnetic saturation behavior. Particularly, it is observed that the post-annealing in different atmospheres does not change the essential FM of the samples but does change significantly the saturated magnetic moments $\left(M_{s}\right)$ of the samples.

3.5. Discussion. The mechanism of intrinsic FM in TM doped oxides still remains controversial, whether it is an intrinsic or extrinsic property of these materials. A diversity of theories has been proposed. For instance, the magnetism of the TM doped $\mathrm{ZnO}$ has been attributed to ferromagnetic coupling of the local moment of TM dopants through the carrier-mediated Ruderman-Kittel-Kasuya-Yosida (RKKY) interaction [21], indirect double-exchange [22, 23] or superexchange [24], and so forth. There are even proposals that the observed FM originate from the local magnetic moment of defects such as the $\mathrm{Zn}$ vacancies [25] or O vacancies [2629]. 


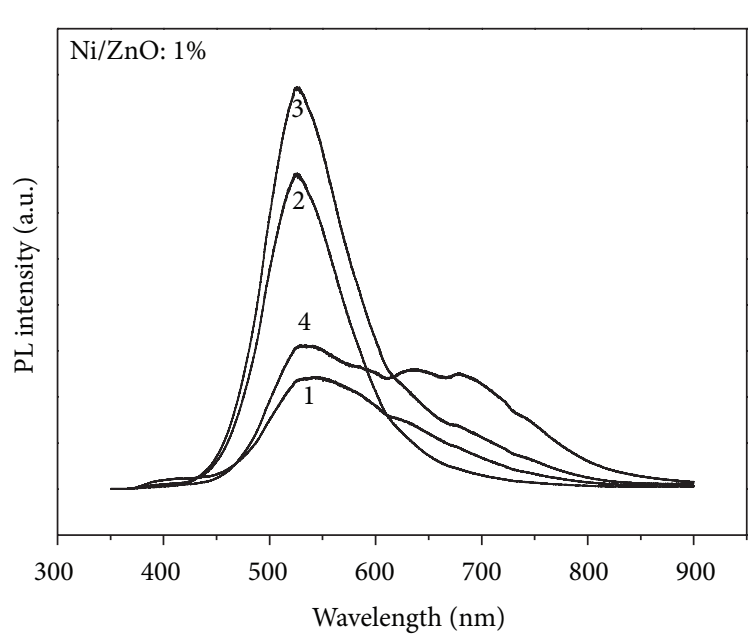

(1) As grown

(2) Annealing in $\mathrm{Ar}$

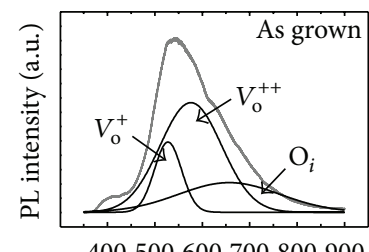

400500600700800900

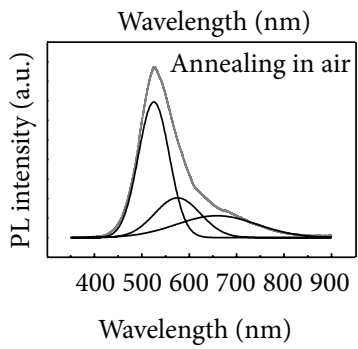

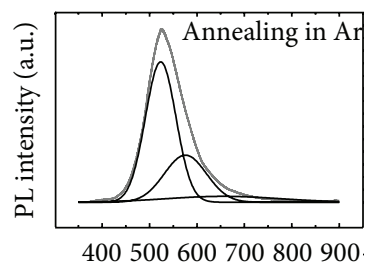

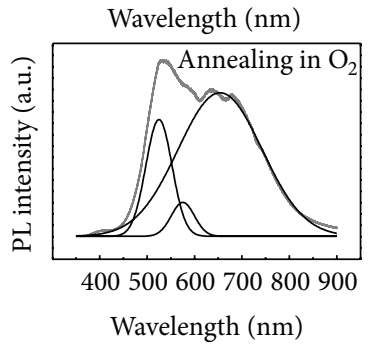

(b)

FIGURE 3: RT photoluminescence spectra of Ni doped $\mathrm{ZnO}$ samples as grown and annealed in different atmosphere (a) and Gaussian fit of each PL spectrum (b) (The gray lines are the experimental results and the black solid curves are Gaussian fits).

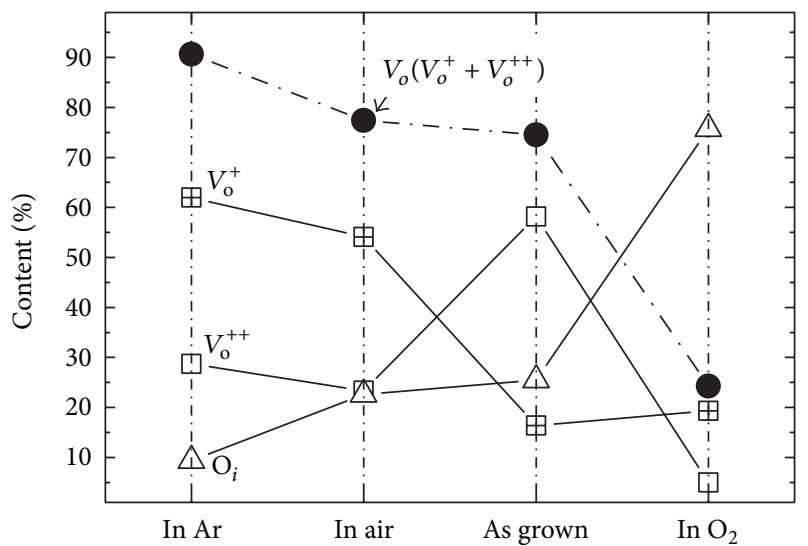

FIGURE 4: The contents of oxygen related defects $\left(V_{o}^{+}, V_{o}^{++}\right.$and $\left.\mathrm{O}_{i}\right)$ in as grown $\mathrm{Ni}$ doped $\mathrm{ZnO}$ nanoparticles, and samples with thermal annealing in $\mathrm{O}_{2}$, air, and Ar, respectively.

In the present work, XRD and XPS results clearly demonstrate that the samples have a single wurtzite phase and there is no indication of additional phases, such as the $\mathrm{Ni}$ magnetic precipitation. So, we expect that FM is from an intrinsic exchange interaction of magnetic moments in $\mathrm{Ni}$ doped $\mathrm{ZnO}$. Although the exact mechanism of intrinsic FM in Ni doped oxides is still under debate, defects have greatly been suggested to play an important role in the magnetic origin in the $\mathrm{Ni}$ doped $\mathrm{ZnO}$ system. As the postannealing is expected to have remarked effects on the defects rather than on the TM dopants, the combination of the present defects analyses based on the PL and the magnetic measurements provides a good opportunity to clarify the physical nature of the local magnetic moment.

In the PL results, $\mathrm{Zn}$ vacancies and interstitials were not observed in the prepared $\mathrm{Ni}$ doped $\mathrm{ZnO}$ system. So the

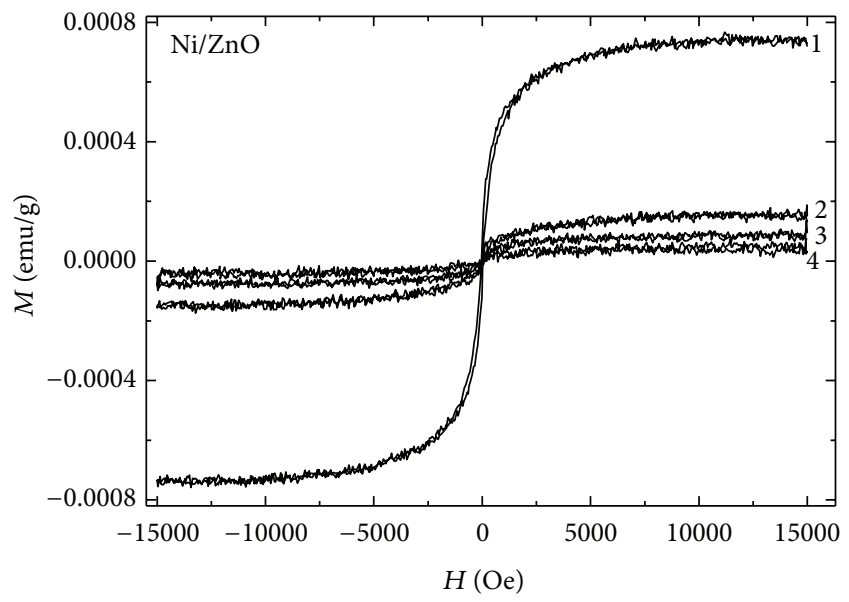
(1) In $\mathrm{Ar}$
(3) As grown
(2) In air
(4) In $\mathrm{O}_{2}$

Figure 5: Magnetic hysteresis of $\mathrm{Ni}$ doped $\mathrm{ZnO}$ samples as grown and postannealed in different atmospheres $\left(\mathrm{O}_{2}\right.$, air, and $\left.\mathrm{Ar}\right)$.

contributions of the observed oxygen defects on FM will be discussed below.

From Figure 5 it is observed that the saturated magnetic moment increases after annealing in Ar and air but decreases after annealing in $\mathrm{O}_{2}$. We compared the saturated magnetic moments with the optical spectroscopic intensities originated from the oxygen vacancies in two charge states and oxygen interstitials (Figure 4 ). A definitely positive correlation between the $M_{s}$ and the intensity of $V_{o}\left(V_{o}^{+}\right.$and $\left.V_{o}^{++}\right)$is observed, while a pronounced negative correlation between the $M_{s}$ and the intensity of $\mathrm{O}_{i}$ can be seen. These results indicate that the observed three different defects may make different contributions to FM and that oxygen vacancies and 
its related defect complexes play an essential role in the $\mathrm{Ni}$ doped $\mathrm{ZnO}$ system. As the annealing in different atmospheres does not change the concentration of the Ni dopants, it is expected that the dominant differences of FM introduced by annealing among the samples are either the concentrations or the charge states of the oxygen related defects, such as oxygen vacancies $\left(V_{o}\right)$ and $V_{o}$-Ni complexes.

Theoretical and experimental studies have later confirmed that ferromagnetism in transition metal doped $\mathrm{ZnO}$ system, especially in $\mathrm{ZnO}$ thin film, is genuine and commonly believed to be due to an exchange interaction between magnetic moments localized at the TM sites mediated by free charge carriers. And, the magnetic moment can actually be mediated by tuning the concentration of lattice defects, as well as that of the dopants [30]. In the present $\mathrm{ZnO}$ :Ni samples, there may coexist two different mechanisms in response to the observed magnetism. There is an indirect RKKY interaction among the magnetic dopants/defects, which is always ferromagnetic in the short-range regime. In addition, there is the antiferromagnetic superexchange interaction via the $\mathrm{O}$ anions. The observed magnetism depends on the competition of these two mechanisms. With increasing the oxygen vacancies, the antiferromagnetic superexchange is suppressed so that the positive correlation between the $M s$ and the intensity of oxygen vacancy is observed. In any sense, based on the present results, we suggest that in addition to the magnetic doping effect, oxygen vacancies, especially $V_{o}^{+}$, play an essential role in the magnetic origin for $\mathrm{Ni}$ doped $\mathrm{ZnO}$. The role of oxygen defects in mediating the FM in TM doped $\mathrm{ZnO}$ still needs further theoretical and experimental research.

\section{Conclusion}

In summary, $\mathrm{Ni}$ doped $\mathrm{ZnO}$ nanoparticles have been prepared with a solution method. The structure and the surface valence states of the elements in the samples were studied in detail. To investigate the influence of the defects on the inducing magnetic, the particles are annealed in $\mathrm{O}_{2}$, air, and Ar, respectively. RT PL spectra were measured to facilitate an investigation of the defects. Magnetization loops for the samples were measured at $300 \mathrm{~K}$ and clearly show typical ferromagnetic saturation behavior. A combination of results from the defects analyses based on the PL and the magnetic measurements suggest that oxygen vacancies, especially singly ionized oxygen vacancies, play a crucial role in mediating ferromagnetism in the $\mathrm{Ni}$ doped $\mathrm{ZnO}$ system.

\section{Conflict of Interests}

All the authors declare that they do not have any conflict of interests.

\section{Acknowledgments}

The work is supported by the National Science Foundation of China (Grant no. 61076089), the Shanghai Natural Science Foundation (Grant no. B10ZR1412400), and the National Natural Science Foundation (Grant no. 61204105).

\section{References}

[1] G. A. Prinz, "Magnetoelectronics," Science, vol. 282, no. 5394, pp. 1660-1663, 1998.

[2] S. A. Wolf, D. D. Awschalom, R. A. Buhrman et al., "Spintronics: a spin-based electronics vision for the future," Science, vol. 294, no. 5546, pp. 1488-1495, 2001.

[3] T. Dietl, H. Ohno, F. Matsukura, J. Cibert, and D. Ferrand, "Zener model description of ferromagnetism in zinc-blende magnetic semiconductors," Science, vol. 287, no. 5455, pp. 10191022,2000

[4] S. W. Jung, S. J. An, G. C. Yi et al., "Ferromagnetic properties of $\mathrm{Zn}_{1-x} \mathrm{Mn}_{x} \mathrm{O}$ epitaxial thin films," Applied Physics Letters, vol. 80, article 4561, 2002.

[5] C. Xu, J. Chun, D. Kim et al., "Structural characterization and low temperature growth of ferromagnetic $\mathrm{Bi}-\mathrm{Cu}$ codoped $\mathrm{ZnO}$ bicrystal nanowires," Applied Physics Letters, vol. 91, Article ID 153104, 2007.

[6] T. S. Herng, S. P. Lau, S. F. Yu, J. S. Chen, and K. S. Teng, "Zninterstitial-enhanced ferromagnetism in $\mathrm{Cu}$-doped $\mathrm{ZnO}$ films," Journal of Magnetism and Magnetic Materials, vol. 315, no. 2, pp. 107-110, 2007.

[7] D. Q. Gao, Z. H. Zhang, J. L. Fu, Y. Xu, J. Qi, and D. S. Xue, "Room temperature ferromagnetism of pure $\mathrm{ZnO}$ nanoparticles," Journal of Applied Physics, vol. 105, Article ID 113928, 2009.

[8] B. B. Straumal, A. A. Mazilkin, S. G. Protasova et al., "Magnetization study of nanograined pure and $\mathrm{Mn}$-doped $\mathrm{ZnO}$ films: formation of a ferromagnetic grain-boundary foam," Physical Review B, vol. 79, no. 20, Article ID 205206, 2009.

[9] W. Liu, W. Li, Z. Hu, Z. Tang, and X. Tang, "Effect of oxygen defects on ferromagnetic of undoped ZnO," Journal of Applied Physics, vol. 110, no. 1, Article ID 013901, 2011.

[10] S. Asbrink, A. Waśkowska, L. Gerward, J. Staun Olsen, and E. Talik, "High-pressure phase transition and properties of spinel ZnMn2O4," Physical Review B, vol. 60, no. 18, Article ID 12656, 1999.

[11] J. H. Li, D. Z. Shen, J. Y. Zhang et al., "Magnetism origin of Mndoped $\mathrm{ZnO}$ nanoclusters," Journal of Magnetism and Magnetic Materials, vol. 302, pp. 118-121, 2006.

[12] Y. Liu, S. H. Yang, Y. L. Zhang, and D. H. Bao, "Influence of annealing temperature on structural, optical and magnetic properties of $\mathrm{Mn}$-doped $\mathrm{ZnO}$ thin films prepared by sol-gel method," Journal of Magnetism and Magnetic Materials, vol. 321, pp. 3406-3410, 2009.

[13] S. Baek, J. Song, and S. Lim, "Improvement of the optical properties of $\mathrm{ZnO}$ nanorods by Fe doping," Physica B, vol. 399, no. 2, pp. 101-104, 2007.

[14] C. Y. Lin, W. H. Wang, C.-S. Lee, K. W. Sun, and Y. W. Suen, "Magnetophotoluminescence properties of Co-doped ZnO nanorods," Applied Physics Letters, vol. 94, Article ID 151909, 2009.

[15] A. Van Dijken, E. A. Meulenkamp, D. Vanmaekelbergh, and A. Meijerink, "Luminescence of nanocrystalline $\mathrm{ZnO}$ particles: the mechanism of the ultraviolet and visible emission," Journal of Luminescence, vol. 87, pp. 454-456, 2000.

[16] A. K. Srivastava, M. Deepa, N. Bahadur, and M. S. Goyat, "Influence of Fe doping on nanostructures and photoluminescence of sol-gel derived ZnO," Materials Chemistry and Physics, vol. 114, no. 1, pp. 194-198, 2009.

[17] K. Vanheusden, C. H. Seager, W. L. Warren, D. R. Tallant, and J. A. Voigt, "Correlation between photoluminescence and oxygen 
vacancies in ZnO phosphors," Applied Physics Letters, vol. 68, no. 3, pp. 403-405, 1996.

[18] X. L. Wu, G. G. Siu, C. L. Fu, and H. C. Ong, "Photoluminescence and cathodoluminescence studies of stoichiometric and oxygen-deficient ZnO films," Applied Physics Letters, vol. 78, article 2285, 2001.

[19] B. Panigrahy, M. Aslam, D. Shanker Misra, M. Ghosh, and D. Bahadur, "Defect-Related Emissions and Magnetization Properties of ZnO Nanorods," Advanced Functional Materials, vol. 20, pp. 1161-1165, 2010.

[20] S. A. Studenikin, N. Golego, and M. Cocivera, "Fabrication of green and orange photoluminescent, undoped $\mathrm{ZnO}$ films using spray pyrolysis," Journal of Applied Physics, vol. 84, no. 4, pp. 2287-2294, 1998.

[21] P. Bruno and C. Chappert, "Oscillatory coupling between ferromagnetic layers separated by a nonmagnetic metal spacer," Physical Review Letters, vol. 67, no. 12, pp. 1602-1605, 1991.

[22] C. Zener, "Interaction between the $d$-shells in the transition metals-II. Ferromagnetic compounds of manganese with perovskite structure," Physical Review, vol. 82, pp. 403-405, 1951.

[23] P. W. Anderson and H. Hasegawa, "Considerations on double exchange," Physical Review, vol. 100, no. 2, pp. 675-681, 1955.

[24] H. Katayama-Yoshida, K. Sato, T. Fukushima et al., "Theory of ferromagnetic semiconductors," Physica Status Solidi A, vol. 204, no. 1, pp. 15-32, 2007.

[25] W. S. Yan, Z. H. Sun, and Q. H. Liu, "Zn vacancy induced roomtemperature ferromagnetism in Mn-doped $\mathrm{ZnO}$," Applied Physics Letters, vol. 91, Article ID 062113, 2007.

[26] C. H. Patterson, "Role of defects in ferromagnetism in $\mathrm{Zn}_{1-x} \mathrm{Co}_{x} \mathrm{O}$ : a hybrid density-functional study," Physical Review $B$, vol. 74, Article ID 144432, 2006.

[27] N. H. Hong, J. Sakai, N. T. Huong, N. Poirot, and A. Ruyter, "Role of defects in tuning ferromagnetism in diluted magnetic oxide thin films," Physical Review B, vol. 72, no. 4, Article ID 045336, 2005.

[28] E.-Z. Liu, Y. He, and J. Z. Jiang, "Ferromagnetism induced by defect complex in Co-doped ZnO," Applied Physics Letters, vol. 93, Article ID 132506, 2008.

[29] C. W. Zhang and S. S. Yan, "Origin of ferromagnetism of Co-doped $\mathrm{SnO}_{2}$ from first-principles calculations," Journal of Applied Physics, vol. 106, Article ID 063709, 2009.

[30] X. L. Wang, C. Y. Luan, and Q. Shao, "Effect of the magnetic order on the room-temperature band-gap of Mn-doped $\mathrm{ZnO}$ thin films," Applied Physics Letters, vol. 102, Article ID 102112, 2013. 

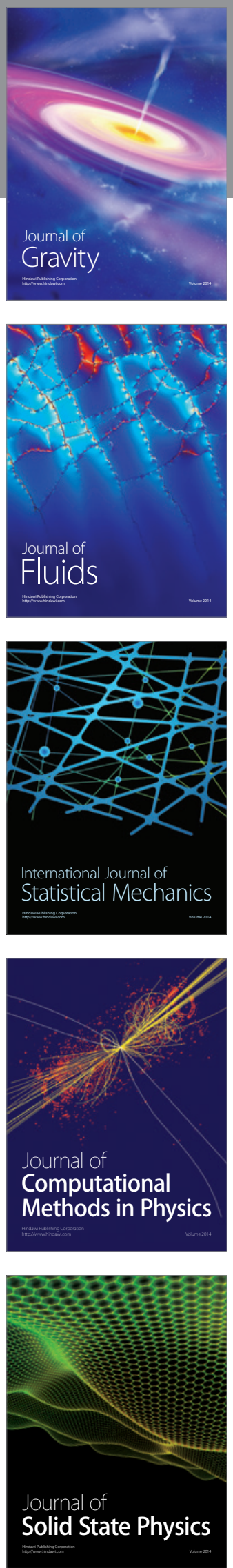

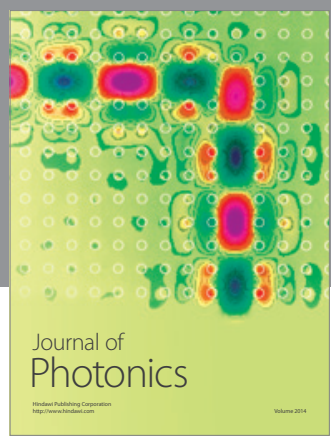

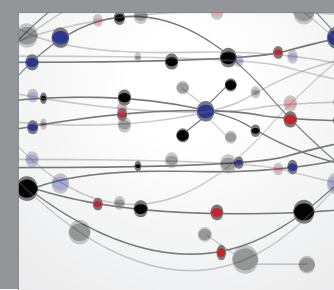

The Scientific World Journal

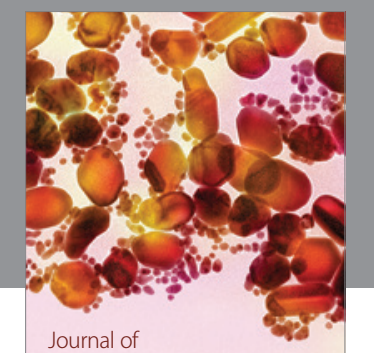

Soft Matter
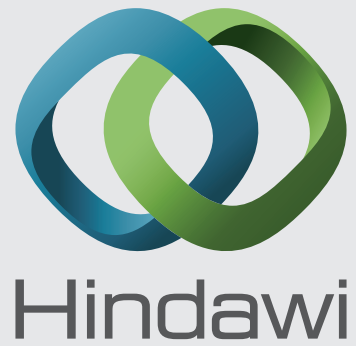

Submit your manuscripts at

http://www.hindawi.com
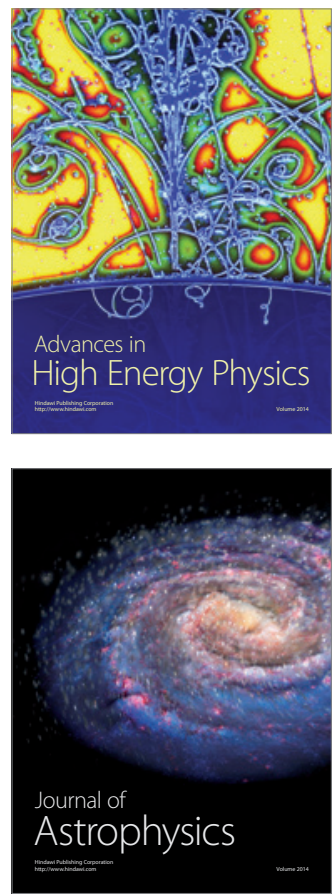
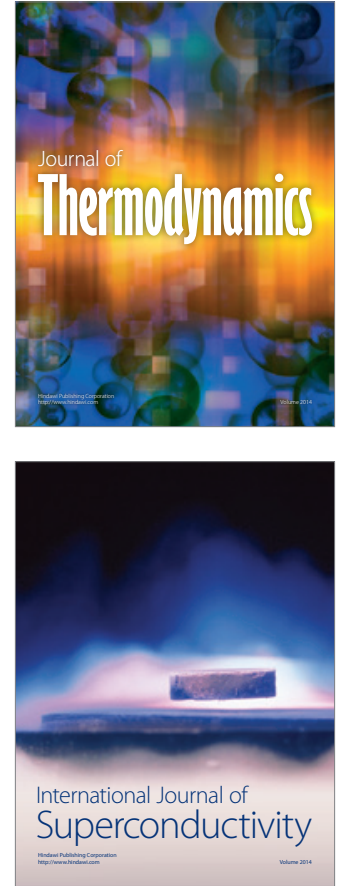
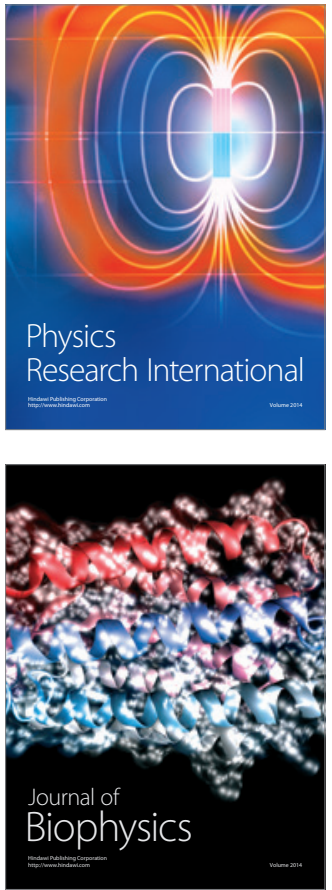
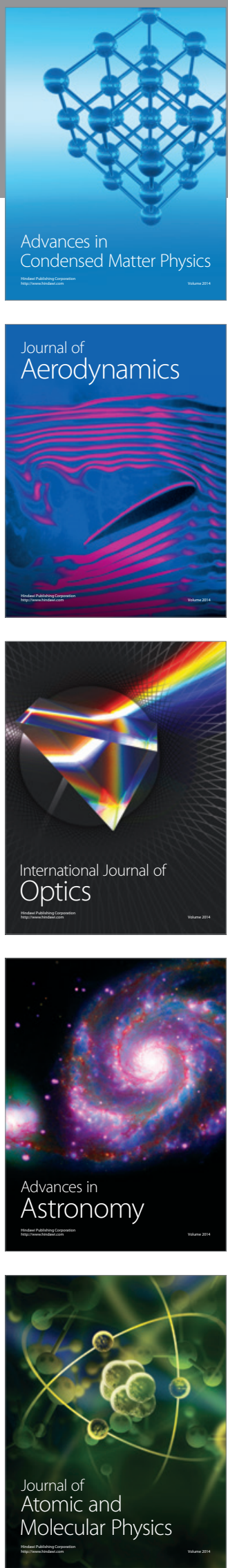